\title{
Bone Marrow Cell Transplantation Restores Olfaction in the Degenerated Olfactory Bulb
}

\author{
David Díaz, ${ }^{1,2 \star}$ Gabriel Lepousez, ${ }^{3,4 \star}$ Gilles Gheusi, ${ }^{3,4}$ José Ramón Alonso, ${ }^{1,2,5}$ Pierre-Marie Lledo, ${ }^{3,4}$ \\ and Eduardo Weruaga ${ }^{1,2}$ \\ ${ }^{1}$ Laboratory of Neuronal Plasticity and Neurorepair, Institute for Neuroscience of Castilla y León (INCyL) and 2Institute of Biomedical Research of \\ Salamanca, Universidad de Salamanca, E-37007 Salamanca, Spain, ${ }^{3}$ Institut Pasteur, Laboratory for Perception and Memory and ${ }^{4}$ CNRS, Unité de \\ Recherche Associée 2182, 75724 Paris, France, and 5Instituto de Alta Investigación, Universidad de Tarapacá, Arica, Chile
}

Bone marrow contains heterogeneous cell types including end-lineage cells, committed tissue progenitors, and multipotent stem/progenitor cells. The immense plasticity of bone marrow cells allows them to populate diverse tissues such as the encephalon, and give rise to a variety of cell types. This unique plasticity makes bone marrow-derived cells good candidates for cell therapy aiming at restoring impaired brain circuits. In the present study, bone marrow cells were transplanted into P20 mice that exhibit selective olfactory degeneration in adulthood between P60 and P150. These animals, the so-called Purkinje Cell Degeneration (PCD) mutant mice, suffer from a progressive and specific loss of a subpopulation of principal neurons of the olfactory bulb, the mitral cells (MCs), sparing the other principal neurons, the tufted cells. As such, PCD mice constitute an interesting model to evaluate the specific role of MCs in olfaction and to test the restorative function of transplanted bone marrow-derived cells. Using precision olfactometry, we revealed that mutant mice lacking MCs exhibited a deficit in odorant detection and discrimination. Remarkably, the transplantation of wild-type bone marrowderived cells into irradiated PCD mutant mice generated a large population of microglial cells in the olfactory bulb and reduced the degenerative process. The alleviation of MC loss in transplanted mice was accompanied by functional recovery witnessed by significantly improved olfactory detection and enhanced odor discrimination. Together, these data suggest that: (1) bone marrow-derived cells represent an effective neuroprotective tool to restore degenerative brain circuits, and (2) MCs are necessary to encode odor concentration and odor identity in the mouse olfactory bulb.

\section{Introduction}

Adult bone marrow-derived cells (BMDCs) can transform into many different lineages (Krause et al., 2001; Wilson and Trumpp, 2006; Álvarez-Dolado, 2007), including neural or glial cells in the encephalon (Brazelton et al., 2000; Mezey et al., 2000). In the brain, BMDCs mainly give rise to resting microglial cells, but some of them acquire a neuronal fate through cell fusion or after transdifferentiation (Álvarez-Dolado et al., 2003; Corti et al., 2004; Massengale et al., 2005; Bae et al., 2007). Both cellular processes occur simultaneously depending on the cell type formed (Recio et al., 2011). In the olfactory bulb (OB), the capacity of

Received Jan. 18, 2012; revised April 6, 2012; accepted May 3, 2012.

Author contributions: D.D., G.L., G.G., P.-M.L., and E.W. designed research; D.D., G.L., and G.G. performed research; J.R.A. contributed unpublished reagents/analytic tools; D.D., G.L., G.G., P.-M.L., and E.W. analyzed data; P.-M.L. and E.W. wrote the paper.

This work was supported by the Ministerio de Ciencia e Innovación (BFU2010-18284), the Junta de Castilla y León, the Centre for Regenerative Medicine and Cell Therapy of Castile and León, the Fundación Samuel Solórzano, the University of Salamanca. Lledo's laboratory is supported by the life insurance company Aprionis, the Fondation pour la Recherche Médicale, the labex Revive, and the Agence Nationale de la Recherche (Grants ANR-BLAN-SVSE4LS-110624 and ANR-09-NEUR-004) in the frame of ERA-NET NEURON of FP7 program by the European Commission. We thank Dr. Matt Valley and Dr. Françoise Lazarini for critical reading of the manuscript.

*D.D. and G.L. contributed equally to this work.

Correspondence should be addressed to either Dr. Eduardo Weruaga, INCyL, Universidad de Salamanca, C/ Pintor Fernando Gallego 1, E-37007, Salamanca, Spain, E-mail: ewp@usal.es; or Dr. Pierre-Marie Lledo, Institut Pasteur, 25 rue du Dr. Roux, 75724 Paris Cedex, France, E-mail: pmlledo@pasteur.fr.

DOI:10.1523/JNEUROSCI.0260-12.2012

Copyright $\odot 2012$ the authors $\quad 0270-6474 / 12 / 329053-06 \$ 15.00 / 0$
BMDCs to generate new neurons is rather limited (Brazelton et al., 2000; Corti et al., 2004; Recio et al., 2011). Accumulating data from cell-based therapies for brain repair also indicate that neuroprotection may occur even in the absence of efficient cell replacement. However, little is known about neuroprotective effects of BMDCs in a neurodegenerative context (Rodríguez et al., 2007; Uccelli et al., 2011).

In the present study, we have used the Purkinje Cell Degeneration (PCD) mutant mouse as a model to study the potential restorative function of BMDCs on protracted neurodegeneration. Animals carrying the $p c d$ mutation experience a dramatic loss of Purkinje neurons early in postnatal development, leading to severe cerebellar ataxia (Mullen et al., 1976; Wang and Morgan, 2007). In the adult OB, mutant mice progressively loose mitral cells (MC) but not the other population of output neurons called tufted cells (Greer and Shepherd, 1982; Greer and Halász, 1987; Bartolomei and Greer, 1998; Recio et al., 2007). Although the impact of selective degeneration of bulbar relay neurons has been extensively described at a morphological level (Greer and Shepherd, 1982; Greer and Halász, 1987; Bartolomei and Greer, 1998), little is known about the olfactory capacity of these animals lacking MCs. Moreover, morphological and electrophysiological characterization of MC and tufted cell populations suggest that both output neurons convey different aspects of odor information. Compared with MCs, tufted cells exhibit a much lower threshold of odor activation and a larger gain in respect to odor 
concentration, suggesting an important role for odor detection (Nagayama et al., 2004; Griff et al., 2008; Mori and Sakano, 2011). The specific loss of the MC population in adulthood makes the PCD mutant mouse an attractive model to test this conjecture. We predicted that the selective loss of MC in PCD mice could spare the ability of the animals to detect odorants but could affect other olfactory faculties such as odor discrimination and/or learning. Using precision olfactometry, we examined whether $\mathrm{MC}$ loss, and the resulting olfactory impairments, could be restored by BMDC transplantation.

\section{Materials and Methods}

Animals. Four groups of male mice of the C57BL/DBA strain were used $(n=46)$, divided between transplanted or nontransplanted mice with two different phenotypes within two groups: wild-type (WT) and PCD. Transgenic green fluorescent protein (GFP) (Hadjantonakis et al., 1998) mice were selected as bone marrow donors for transplants. Mice were housed, manipulated, and killed in accordance with current European (86/609/ECC and directive 2003/65/CE) and Spanish (RD 1201/2005 and law 32/2007) legislation and local ethical committees.

Isolation and transplantation of bone marrow stem cells. Donors (4- to 8 -weeks-old) were killed by cervical dislocation, and the femurs and tibias were dissected. Bone marrow stem cells isolation was performed as previously described (Díaz et al., 2011; Recio et al., 2011). Briefly, bone marrow was extracted from both epiphyses of the bone, then filtered and centrifuged (1500 rpm, $5 \mathrm{~min}$ ). After erythrocyte lysis $\left(140 \mathrm{~mm} \mathrm{NH}_{4} \mathrm{Cl}\right.$, $17 \mathrm{~mm}$ Tris-base, $\mathrm{pH}$ 7.4), the cell suspension were resuspended in $0.1 \mathrm{M}$ PBS, pH 7.4. The bone marrow of the recipients was ablated at P19 with a gamma irradiation device (model Gammacell 1000 Elite; MDS Nordion; radiation rate, $243 \mathrm{cGy} / \mathrm{min}$ ) with a ${ }^{137} \mathrm{Cs}$ source, and the mice were housed separately in an insulated rack specific for immunodepressed animals for 2 weeks. Cells $\left(7.5 \times 10^{6}\right)$ were transplanted in each animal through an injection in the tail vein at P20. Some irradiated mice were not subjected to the transplantation process to check the efficacy of the bone marrow ablation $(n=6)$. To check for the correct assimilation of the transplant, blood samples were collected $14,28,42$, and $130 \mathrm{~d}$ posttransplantation. After erythrocyte lysis $\left(0.83 \% \mathrm{w} / \mathrm{v} \mathrm{NH} \mathrm{N}_{4} \mathrm{Cl}, 0.1 \% \mathrm{w} / \mathrm{v}\right.$ $\mathrm{KHCO}_{3}, 0.372 \% \mathrm{w} / \mathrm{v}$ EDTA, pH 7.3), the cell suspension was resuspended in PBS. Then, the percentage of GFP-positive cells was measured by flow cytometry (FACSCalibur; Becton Dickinson) as previously described (Díaz et al., 2011; Recio et al., 2011).

Olfactometry. Mice were trained in custom-built computer-controlled eight-channel air-dilution olfactometers (www.olfacto-meter.com) (Lazarini et al., 2009). Briefly, solenoid pinch valves controlled purified air streams, passing over the surface of mineral oil-diluted odorants. This odorized air was diluted 1:40 in odor-free air before its introduction into an odor sampling tube in the mouse operant chamber. The odorants used were $(+)$-carvone and (-)-carvone (99\%; Sigma Aldrich). Partially water-deprived mice $(80-85 \%$ of their baseline body weight) were trained using an operant conditioning go/no-go paradigm. Standard operant conditioning methods were used to train mice to insert their snouts into the odor sampling port for at least $1.2 \mathrm{~s}$ and to respond by licking the water delivery tube (within the same port) to get a water reward $(3 \mu \mathrm{l})$ in the presence of a positive odor stimuli, $(+)$-carvone (reinforced stimulus: $\mathrm{S}+$ ), and to refrain from licking and retract their head from the sampling port in the presence of a negative odor stimulus (unreinforced stimulus: S-; see Fig. $2 A$ ). In each trial, a single stimulus was presented and $\mathrm{S}+$ and $\mathrm{S}-$ trials were presented in a modified random order. The percentage of appropriate responses was determined for each block of 20 trials. A score of $\geq 85 \%$ implied that mice had correctly learned to assign reward/nonreward values. Each mouse underwent a session of 10 blocks (200 trials) per day. Mice were first trained with $(+)$-carvone versus mineral oil, reaching a plateau of performance after 30 blocks. Decreasing concentrations of odorant were used to determine their odor detection threshold: $\left[10^{-1}\right],\left[10^{-2}\right],\left[10^{-3}\right],\left[10^{-4}\right]$, and $\left[10^{-5}\right]$. For odorant discrimination tests, two odorants were used: $(+)$-carvone as $\mathrm{S}+$ and $(-)$-carvone as $\mathrm{S}-$, both diluted to $\left[10^{-1}\right]$. After discrimination of the pure odorant molecules (100:100), we tested odor discrimination thresh- old by gradually presenting binary odor mixtures of those carvone enantiomers: 80:20 (80\% (+)-carvone/20\% (-)-carvone for S+, and $80 \%$ $(-)$-carvone/20\% (+)-carvone the $\mathrm{S}-)$, 68:32, and 56:44. The reaction time between odor arrival and head retraction was also measured at $\left[10^{-1}\right]$.

Immunohistochemistry. Anesthetized animals were perfused intracardially with a $0.9 \% \mathrm{NaCl}$, followed by $5 \mathrm{ml} / \mathrm{g} 4 \%$ paraformaldehyde in $0.1 \mathrm{~m}$ phosphate buffer. Brains were dissected and postfixed for $2 \mathrm{~h}$. After cryoprotection, $40-\mu \mathrm{m}$-thick slices were cut with a freezing-sliding microtome (Leica). Free-floating sections were labeled with the following primary antibodies: goat anti-GFP (1:2000; Abcam) to detect GFP+ transplanted BMDCs, mouse anti-reelin (1:1000; Millipore Bioscience Research Reagents) to detect MCs, rabbit anti-Ki67 (1:500; Abcam) to detect proliferating cells in neurogenic zones, goat anti-olfactory marker protein (OMP) (1:10,000; Wako), rabbit anti-GAP43 (1:500; Milipore) to analyze the olfactory glomerular innervation, and rabbit anti-Ibal (1:1000; Wako) to detect microglia. Appropriate secondary antibodies conjugated to Cy2, Cy3, or Cy5 (1:500; Jackson) were used to reveal the primary antibodies. Sections were counterstained with DAPI or propidium iodide, mounted and observed using DP70 digital camera attached to a Provis AX70 microscope (both from Olympus). One-in-six series of $\mathrm{OB}$, rostral migratory stream (RMS; bregma: $2.5 \mathrm{~mm}$ ), and subventricular zone (SVZ; bregma: $1 \mathrm{~mm}$ ) coronal sections were used for quantification (6 sections per brain) using the Neurolucida software (MicroBrightField).

Statistical analysis. All data are shown as mean \pm SEM. Repeatedmeasures ANOVA (rm-ANOVA) over session, two-way ANOVA, and post hoc tests were used to analyze behavioral data and the evolution of GFP cell density with genotype (WT vs PCD), grafting (grafted vs nongrafted), or age as factors. Student's $t$ test was then used to analyze possible differences in MC density and in behavioral performances between transplanted and nontransplanted PCD mice.

\section{Results \\ Transplantation and integration of BMDCs into the OB circuit}

Irradiation is one of the most widespread methodologies to perform efficient bone marrow cell transplantation (Álvarez-Dolado et al., 2003; Massengale et al., 2005). In this study, PCD mice (P19) were exposed to an irradiation of 7.5 Gy as a lethal dose (Díaz et al., 2011; Recio et al., 2011). Following irradiation and bone marrow cell transplantation (P20) from GFP donors, only the immunologically reconstituted mice survived $(n=20)$; all nontransplanted irradiated mice died 7-10 d after irradiation $(n=6)$. In addition, analysis of peripheral blood demonstrated a continuous increase in the percentage of GFP + donor-derived blood cells after transplantation, reaching a steady proportion of $\sim 73 \%$ of GFP + cells $130 \mathrm{~d}$ posttransplantation $(73.9 \pm 2.6 \%$ of GFP + cells in WT; $72.7 \pm 3.1 \%$ in PCD, $t$ test, $t_{12}=0.23, p=$ 0.81 ). The accumulation of GFP + cells between P34 and P150 was similar in both PCD and control mice (Genotype $\times$ Age ANOVA, $F_{(1,3)}=50.2, p=0.59$ ), thus demonstrating that the $p c d$ mutation did not affect the progressive incorporation of BMDCs. Collectively, these data suggest that reconstitution of the ablated bone marrow by the transplanted cells, and the efficacy of our transplantation procedure, were not altered in PCD mice.

Morphological and neurochemical analysis of $\mathrm{OB}$ sections from transplanted animals revealed that nearly all GFP+ BMDCs, both from P150 control and PCD mice, were Iba1+ microglial cells (Fig. $1 A-C$ ). They represented at least $\sim 11.5 \%$ of the endogenous microglial cell population and display similar density in transplanted WT and PCD mice, as previously reported (Massengale et al., 2005; Recio et al., 2011). Quantitative analysis of immunostaining for reelin (Fig. $1 D, E$ ) revealed the progressive disappearance of MCs between P60 and P150 in PCD mice (Greer and Shepherd, 1982; Greer and Halász, 1987; Bar- 

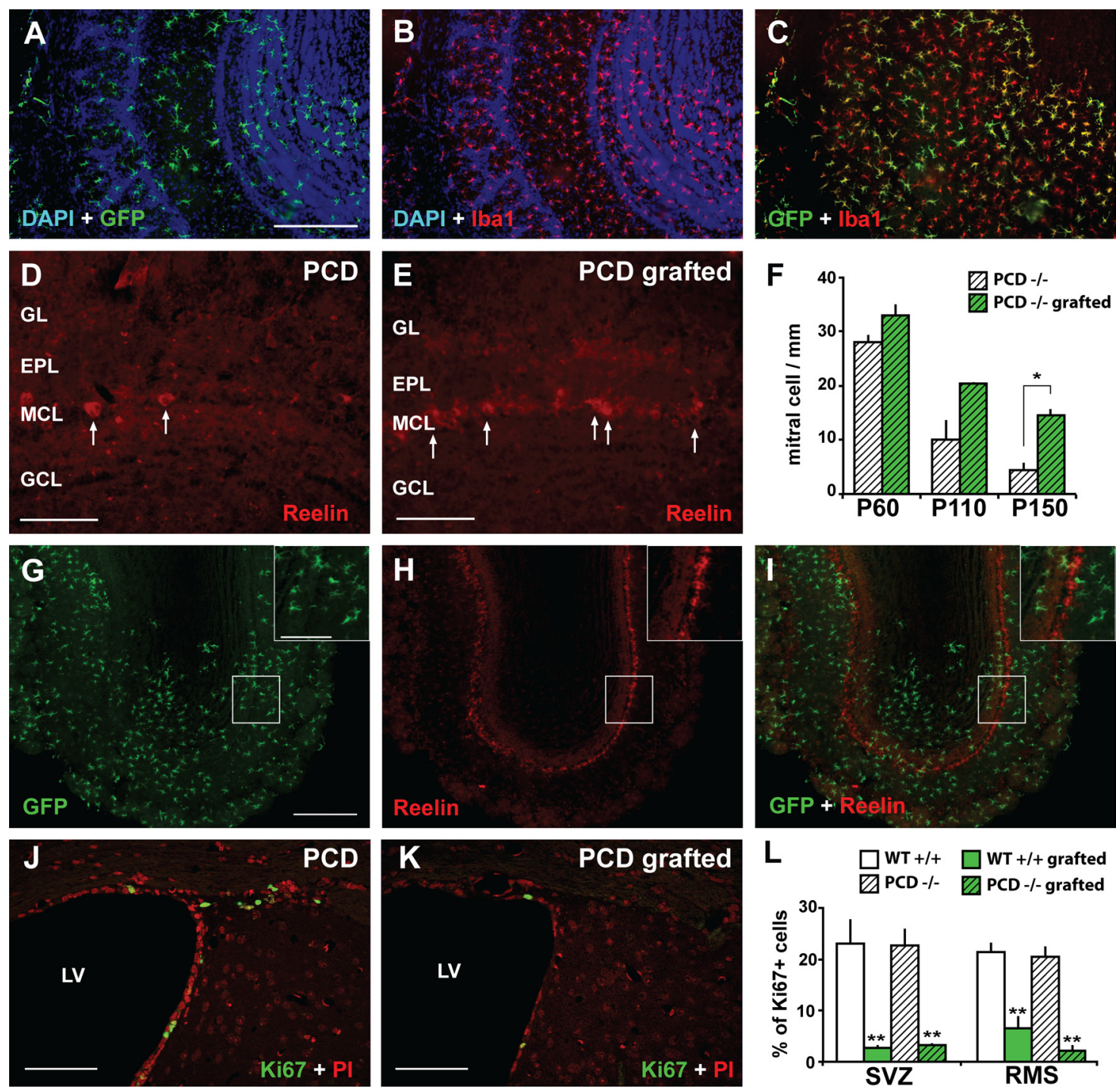

Figure 1. Cellular effects of bone marrow cell transplantation in the olfactory bulb of PCD mice. A-C, GFP + BMDCs (green) expressed microglial marker (Iba1 in red) in the olfactory bulb (counterstaining with DAPI, blue) and display a highly ramified morphology typical of microglia. Scale bar, $200 \mu \mathrm{m} . \boldsymbol{D}, \boldsymbol{E}, \mathrm{MC}$ somata (arrows) in PCD (D) and grafted PCD mice (E) labeled with antibodies against reelin (red). GL, Glomerular layer; EPL, external plexiform layer; MCL, mitral cell layer; GCL, granule cell layer. Scale bars, $100 \mu \mathrm{m}$. $\boldsymbol{F}$, Evolution of MC density in PCD and grafted $P C D$ animals. Student's $t$ test, ${ }^{* *} p<0.01$. G-I, Coronal view of a transplanted mouse OB. GFP+ BMDCs (green; $\mathbf{G}, \boldsymbol{I}$ ) were spread throughout the entire olfactory bulb, displayed microglial morphology ( $G, I$, inset), but never colocalized with reelin (red; $\boldsymbol{H}, \boldsymbol{I})$. Scale bar, $250 \mu \mathrm{m}$; inset, $100 \mu \mathrm{m}$. J, $\boldsymbol{K}$, Proliferative Ki67-positive cells in the subventricular zone in PCD (J) and grafted PCD [ $\boldsymbol{K}$, counterstaining with propidium iodide (PI)]. LV, Lateral ventricle. Scale bars, $75 \mu \mathrm{m}$. L, Quantification of the proliferation rate (percentage of Ki67+ cells) in the SVZ and RMS in WT (white), grafted WT (green), PCD (hatched white), and grafted PCD (hatched green). Student's $t$ test, ${ }^{* *} p<0.01$.

tolomei and Greer, 1998; Recio et al., 2007). Remarkably, grafted PCD mice had more MCs (grafting effect, $F_{(1,11)}=34.4, p<0.05$; Fig. $1 F$ ). Counting at early stages revealed a slow effect of the transplant at $\mathrm{P} 60(+17.2 \%$ in grafted compared with control mice, $p>0.05)$ and at P110 $(+100.9 \%, p>0.05)$, which became statistically significant at $\mathrm{P} 150\left(+236.4 \%, t_{5}=4.64, p<0.05\right)$. In other words, BMDC transplantation elicited a significant survival of $44.2 \%$ of MCs in PCD mice at P150, whereas the MC density was unaffected in WT (grafted WT, $35.8 \pm 2.20 \mathrm{MCs} / \mathrm{mm}$; nor$\mathrm{malWT}, 36.25 \pm 2.56 \mathrm{MCs} / \mathrm{mm} ; n=4$ for each group; $t_{5}=0.175$, $p>0.1$ ). However, double staining for reelin and GFP failed to detect bone marrow-derived MCs (Fig. 1G-I), suggesting that the difference in cell density did not result from direct transdifferentiation of the BMDC into MCs. Although some studies have reported the transdifferentiation of BMDCs into both local interneurons and olfactory sensory neurons (OSN) in a very limited number (Tsujigiwa et al., 2005; Recio et al., 2011), we could not detect GFP + interneurons or GFP + axon terminals from OSN in the transplanted mice $(n=20)$, ruling out any direct neurogenic effect on OB interneurons and OSNs. In addition, analysis of the glomerular innervation from OSN using OMP and GAP43 immunostaining confirmed that the olfactory epithelium was normal and correctly innervated the $\mathrm{OB}$ after irradiation and transplantation, as previously reported (data not shown) (Tsujigiwa et al., 2005; Recio et al., 2011). To evaluate whether other brain regions could benefit from the transplantation, we also examined two adult neurogenic zones, the SVZ and RMS. Despite a strong reduction in Ki67+ proliferating cells in both SVZ and RMS due to irradiation, the grafting did not rescue the production of adult-born neurons in P150 transplanted PCD animals compared with WT (grafted WT vs grafted PCD in SVZ and RMS, $t$ test, $p>0.13$; Fig. $1 J-L$ ). In the cerebellum, Purkinje cell degeneration, which occurs between P15 and P30 (Wang and Morgan, 2007), remained unchanged after bone marrow trans- 
plantation at P20 (data not shown). All together, our data suggest that bonemarrow transplantation in P20 mice had two major effects: the engraftment of microglial BMDCs in the OB and the partial rescue of $\mathrm{MC}$ degeneration in the $\mathrm{PCD}$ mice.

\section{Olfactory improvement following cell transplantation in the PCD mutant mouse}

Because the survival effect on MCs was stronger at P150, we chose this time point to explore a potential benefit for olfactory behavior. Using a behavioral test compatible with the ataxia of mutant mice (Fig. 2A), we investigated the olfactory deficits of PCD mice and evaluated whether MC survival lead to an olfactory improvement in these mice. Animals were first trained to associate the odor $(+)$-carvone with a reward $(\mathrm{S}+)$ and to retract their head for the odorless mineral oil $(\mathrm{S}-)$. To establish a detection threshold, animals were exposed to $(+)$ carvone over a range of concentrations. When starting at an odor concentration of $10^{-1}$, all mice reached the $85 \%$ performance criterion, demonstrating their normal capacity to detect high concentration odorants (Genotype $\times$ Grafting, $F_{(1,1)}=$ 3.59, $p=0.069)$, although nongrafted PCD mice exhibited lower performance than nongrafted control (Fig. 2B). At $10^{-2}$, PCD mice had significantly lower accuracy compared with controls but, remarkably, grafted PCD mice exhibited a better detection threshold (Genotype $\times$ Grafting, $\left.F_{(1,1)}=10.63, p=0.003\right)$. At $10^{-3}$ and $10^{-4}$, all PCD mice had poor odor detection performances that approached chance level. Finally, at the most diluted concentration $\left(10^{-5}\right)$, no differences among the four experimental groups were found.

Next, we investigated the capacity of mice to discriminate between monomolecular enantiomers, $(+)$-carvone versus $(-)$-carvone. When starting from pure molecules $(100 \%$ each) at a dilution of $10^{-1}$ (defined as an easy task), all mice reached the performance criterion of $85 \%$ of correct choices, although nongrafted PCD mice showed significantly lower accuracy compared with nongrafted controls (Genotype $X$ Grafting, $F_{(1,1)}=9.60, p=0.004$; Fig. $\left.2 C\right)$. When the task was made more complex using binary mixtures (80/20\%, 68/32\%, and $56 / 44 \%$ ), the performance of PCD mice strongly declined and reached almost chance levels during the most difficult task (i.e., 56/44\%). Grafted PCD mice showed better performance compared with nongrafted animals when exposed to a $68 / 32 \%$ binary mixture (Genotype $\times$ Grafting, $F_{(1,1)}=6.45, p=0.017$; Fig. $2 C$ ). From these experiments, we conclude that PCD mice had poor odor detection and limited discrimination that could be partially restored by BMDC transplantation.

The intrinsic cerebellar ataxia of PCD mice could affect the execution of behavioral tests, thus interfering with the olfactory performance of the animals. For this purpose, we measured the reaction time in the motor execution of the head retraction (Fig.
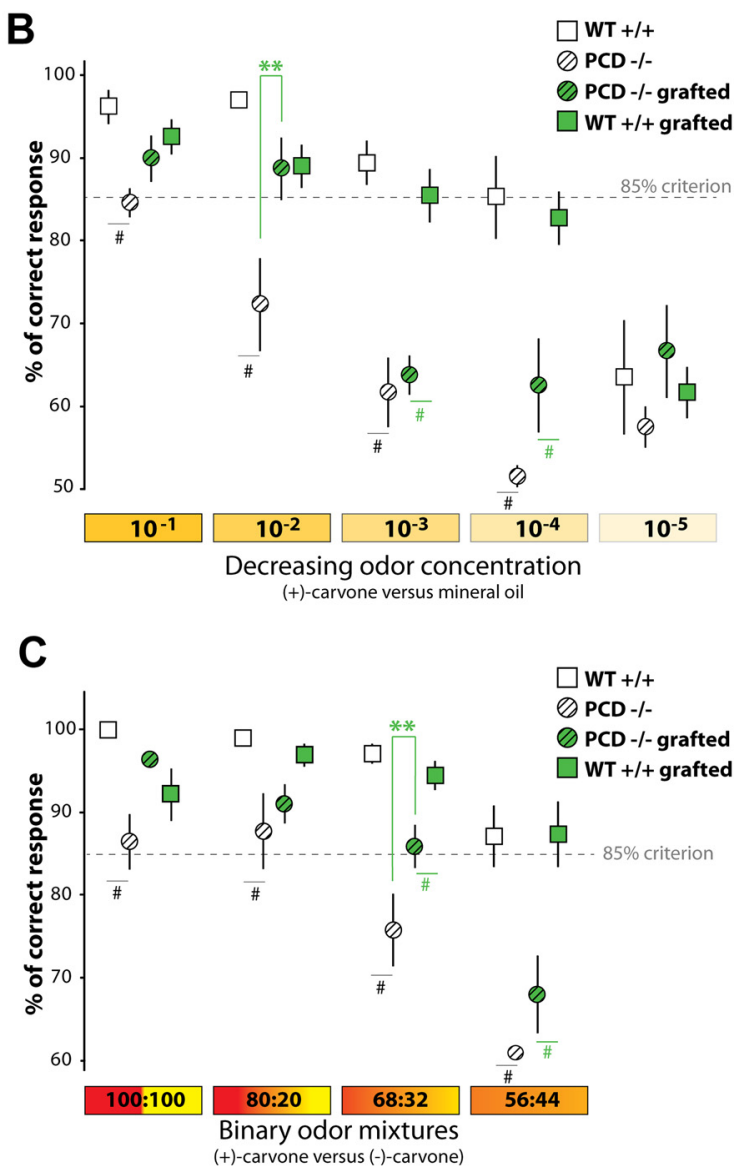

Figure 2. Olfactory performance improvement in PCD mice after BMDC transplantation. $A$, Schematic drawing of the go/no-go . A trial is initiated when the animal breaks the infrared (IR) beam by entering his snout into the sampling port (1). After carvone and $(-)$-carvone $(\boldsymbol{C})$. Wild-type (white squares, $n=8), P C D$ mutant (hatched white circles, $n=7$ ), grafted PCD mutant (hatched green circles, $n=6$ ), and grafted wild-type (green squares, $n=12$ ). Student's $t$ test, ${ }^{* *} p<0.01$; ${ }^{\#} p<0.05$.

$2 A$ ), as a proxy for the motor capacity required to perform our olfactory tests. The reaction time was measured when delivering odorants at $10^{-1}$ because all mice detected this concentration with equal success. No significant differences were found between all groups (Genotype effect, ANOVA, $F_{(1,28)}=0.48, p=$ $0.49 ; 867 \pm 69 \mathrm{~ms}$ for PCD and $706 \pm 66 \mathrm{~ms}$ for WT, $p=0.13$ with $t$ test), suggesting that in our conditions ataxia had no influence on the motor execution required to perform the olfactory task. Finally, we verified that the progression of performance during the initial training, i.e., the learning rate, was comparable between PCD and control mice (Genotype effect, $F_{(1,28)}=0.50$, $p=0.48$ with rm-ANOVA over session), ruling out any potential side effects of the mutation on learning.

\section{Discussion}

We have characterized the effects of transplantation and integration of wild-type BMDCs into the $\mathrm{OB}$ of PCD mutant mice, which show a selective degeneration of MCs between P60 and P150. Following the transplantation starting at P20, BMDCs reached the OB generating microglial cells. Despite the total absence of newly produced MCs or other neuronal cells from BDMCs, the transplantation rescued $44.2 \%$ of MCs from the degeneration in P150 PCD mice. Characterization of the olfactory performances of these animals demonstrate that: (1) bone 
marrow ablation and transplantation does not impair olfactory detection and discrimination in WT, (2) MCs are necessary to perform fine but not coarse odor detection and discrimination, and (3) a partial rescue of MC loss is sufficient to improve both odor detection and discrimination.

Microglial cells were the unique BMDC type detected in the $\mathrm{OB}$ of PCD mice. The absence of GFP + MCs or other neuronal cells in the $\mathrm{OB}$ suggests that wild-type microglial BMDCs may constitute a local source of neuroprotective factors capable of slowing the degenerative process (Derecki et al., 2012), although we cannot discard other effects mediated by blood-circulating factors. Transplanted animals display a significant increased survival of MCs, but we cannot exclude any indirect consequences on other bulbar neuronal populations that could indirectly benefit from the transplantation. Previous studies have demonstrated that bone marrow-derived microglial cells can release neuroprotective substances (Rodríguez et al., 2007; Uccelli et al., 2011) and that healthy transplanted bone marrow can release chemokines and cytokines known to decrease cell apoptosis, suppress immune reactions, and increase angiogenesis, and thus promote neuronal survival (Chen et al., 2003; Chopp et al., 2008). Moreover, it has been reported that microglial BMDCs increase the survival of degenerating neurons at least in other models of brain diseases without any cell replacement (Corti et al., 2004; Derecki et al., 2012). By demonstrating that bone marrow transplantation efficiently provides neuroprotection to degenerative circuits, this study brings new insights into the development of new cell-based therapeutic strategies to promote survival of neuronal cells. Further studies will be necessary to identify the cellular origin and the pharmacological basis of the neuroprotective effects achieved by BMDC transplantation.

Our behavioral experiments demonstrate that both odorant detection and discrimination are severely impaired in mice lacking MCs but not tufted cells. Although our transplantation process strongly reduces the production of adult-born neurons, previous experiments have shown that ablation of adult neurogenesis using irradiation do not impair fine odor discrimination and detection (Lazarini et al., 2009). MC degeneration takes place during adulthood in PCD mice (Greer and Shepherd, 1982; Greer and Halász, 1987; Bartolomei and Greer, 1998), limiting possible compensatory mechanisms of this model in comparison with traditional transgenic animals. Because of their differential morphology, axonal projections to the olfactory cortex, and odor responses, MCs and tufted cells are thought to support different channels of olfactory information (Mori and Sakano, 2011). With a low spike threshold and a large tuning range in respect to odor concentration, tufted cells could be involved in odor intensity coding. With their extended lateral dendrites, MCs show a larger tuning range of lateral inhibition and processed dynamic activity patterns that may be relevant for input comparison and odor discrimination (Nagayama et al., 2004; Griff et al., 2008; Mori and Sakano, 2011). Since tufted cells remain intact in PCD mice (Greer and Shepherd, 1982; Recio et al., 2007), the severe impairment in both detection and discrimination suggest that odor intensity and identity are not conveyed by distinct output neuron categories but rather embedded in MC and tufted cell activity patterns. Moreover, we show that a specific increase in the number of MCs was able to rescue both odor detection and odor discrimination, confirming that olfactory information encoded in MC activity patterns may encompass both odor intensity and odor identity. This conclusion is supported by recent analysis of $\mathrm{MC}$ ensemble activity in mice showing that population trajectories can robustly encode both odor intensity and identity (Bathellier et al., 2008; for descriptions in locust, see Stopfer et al., 2003). Our work is one of the first behavioral studies to parse how the mysterious duet between mitral and tufted cells encodes the olfactory world.

\section{References}

Álvarez-Dolado M (2007) Cell fusion: biological perspectives and potential for regenerative medicine. Front Biosci 12:1-12.

Álvarez-Dolado M, Pardal R, García-Verdugo JM, Fike JR, Lee HO, Pfeffer K, Lois C, Morrison SJ, Alvarez-Buylla A (2003) Fusion of bone-marrowderived cells with Purkinje neurons, cardiomyocytes and hepatocytes. Nature 425:968-973.

Bae JS, Han HS, Youn DH, Carter JE, Modo M, Schuchman EH, Jin HK (2007) Bone marrow-derived mesenchymal stem cells promote neuronal networks with functional synaptic transmission after transplantation into mice with neurodegeneration. Stem Cells 25:1307-1316.

Bartolomei JC, Greer CA (1998) The organization of piriform cortex and the lateral olfactory tract following the loss of mitral cells in PCD mice. Exp Neurol 154:537-550.

Bathellier B, Buhl DL, Accolla R, Carleton A (2008) Dynamic ensemble odor coding in the mammalian olfactory bulb: sensory information at different timescales. Neuron 57:586-598.

Brazelton TR, Rossi FM, Keshet GI, Blau HM (2000) From marrow to brain: expression of neuronal phenotypes in adult mice. Science 290:1775-1779.

Chen J, Li Y, Katakowski M, Chen X, Wang L, Lu D, Lu M, Gautam SC, Chopp M (2003) Intravenous bone marrow stromal cell therapy reduces apoptosis and promotes endogenous cell proliferation after stroke in female rat. J Neurosci Res 73:778-786.

Chopp M, Li Y, Zhang J (2008) Plasticity and remodeling of brain. J Neurol Sci 265:97-101.

Corti S, Locatelli F, Donadoni C, Guglieri M, Papadimitriou D, Strazzer S, Del Bo R, Comi GP (2004) Wild-type bone marrow cells ameliorate the phenotype of SOD1-G93A ALS mice and contribute to CNS, heart and skeletal muscle tissues. Brain 127:2518-2532.

Derecki NC, Cronk JC, Lu Z, Xu E, Abbott SB, Guyenet PG, Kipnis J. (2012) Wild-type microglia arrest pathology in a mouse model of Rett syndrome. Nature 484:105-109.

Díaz D, Recio JS, Baltanás FC, Gómez C, Weruaga E, Alonso JR (2011) Long-lasting changes in the anatomy of the olfactory bulb after ionizing irradiation and bone marrow transplantation. Neuroscience 173:190-205

Greer CA, Halász N (1987) Plasticity of dendrodendritic microcircuits following mitral cell loss in the olfactory bulb of the murine mutant Purkinje cell degeneration. J Comp Neurol 256:284-298.

Greer CA, Shepherd GM (1982) Mitral cell degeneration and sensory function in the neurological mutant mouse Purkinje cell degeneration PCD. Brain Res 235:156-161.

Griff ER, Mafhouz M, Chaput MA (2008) Comparison of identified mitral and tufted cells in freely breathing rats. II. Odor-evoked responses. Chem Senses 33:793-802.

Hadjantonakis AK, Gertsenstein M, Ikawa M, Okabe M, Nagy A (1998) Generating green fluorescent mice by germline transmission of green fluorescent ES cells. Mech Dev 76:79-90.

Krause DS, Theise ND, Collector MI, Henegariu O, Hwang S, Gardner R, Neutzel S, Sharkis SJ (2001) Multi-organ, multi-lineage engraftment by a single bone marrow-derived stem cell. Cell 105:369-377.

Lazarini F, Mouthon MA, Gheusi G, de Chaumont F, Olivo-Marin JC, Lamarque S, Abrous DN, Boussin FD, Lledo PM (2009) Cellular and behavioral effects of cranial irradiation of the subventricular zone in adult mice. PLoS One 4:e7017.

Massengale M, Wagers AJ, Vogel H, Weissman IL (2005) Hematopoietic cells maintain hematopoietic fates upon entering the brain. J Exp Med 201:1579-1589.

Mezey E, Chandross KJ, Harta G, Maki RA, McKercher SR (2000) Turning blood into brain: cells bearing neuronal antigens generated in vivo from bone marrow. Science 290:1779-1782.

Mori K, Sakano H (2011) How is the olfactory map formed and interpreted in the mammalian brain? Annu Rev Neurosci 34:467-499.

Mullen RJ, Eicher EM, Sidman RL (1976) Purkinje cell degeneration, a new neurological mutation in the mouse. Proc Natl Acad Sci U SA 73:208-212. 
Nagayama S, Takahashi YK, Yoshihara Y, Mori K (2004) Mitral and tufted cells differ in the decoding manner of odor maps in the rat olfactory bulb. J Neurophysiol 91:2532-2540.

Recio JS, Weruaga E, Gómez C, Valero J, Briñón JG, Alonso JR (2007) Changes in the connections of the main olfactory bulb after mitral cell selective neurodegeneration. J Neurosci Res 85:2407-2421.

Recio JS, Álvarez-Dolado M, Díaz D, Baltanás FC, Piquer-Gil M, Alonso JR, Weruaga E. (2011) Bone marrow contributes simultaneously to different neural types in the central nervous system through different mechanisms of plasticity. Cell Transplant 20:1179-1192.

Rodríguez M, Álvarez-Erviti L, Blesa FJ, Rodríguez-Oroz MC, Arina A, Melero I, Ramos LI, Obeso JA (2007) Bone-marrow-derived cell differentiation into microglia: a study in a progressive mouse model of Parkinson's disease. Neurobiol Dis 28:316-325.
Stopfer M, Jayaraman V, Laurent G (2003) Intensity versus identity coding in an olfactory system. Neuron 39:991-1004.

Tsujigiwa H, Nishizaki K, Teshima T, Takeda Y, Yoshinobu J, Takeuchi A, Orita Y, Sugata Y, Nagatsuka H, Nagai N (2005) The engraftment of transplanted bone marrow-derived cells into the olfactory epithelium. Brain Res 1052:10-15.

Uccelli A, Benvenuto F, Laroni A, Giunti D (2011) Neuroprotective features of mesenchymal stem cells. Best Pract Res Clin Haematol 24:59-64.

Wang T, Morgan JI (2007) The Purkinje cell degeneration pcd mouse: an unexpected molecular link between neuronal degeneration and regeneration. Brain Res 1140:26-40.

Wilson A, Trumpp A (2006) Bone-marrow haematopoietic-stem-cell niches. Nat Rev Immunol 6:93-106. 